\title{
Is internship training counterproductive for emotional intelli- gence? A follow up study in a cohort of medical graduates in Sri Lanka
}

\author{
Wijekoon $\mathrm{CN}^{1}$, Amaratunga $\mathrm{H}^{2}$, de Silva $\mathrm{Y}^{2}$ \\ Journal of the Ceylon College of Physicians, 2021, 52, 94-100
}

\begin{abstract}
Introduction: Even though emotional intelligence (EI) has gained lot of attention globally, there is scarcity of such data from Sri Lanka. We aimed to determine the effect of internship training of medical graduates on El.
\end{abstract}

Methods: This is a descriptive follow-up study in a cohort of medical graduates of a Sri Lankan university who participated in a baseline study that assessed their El during pre-intern period. Follow up data were collected within 3 months of successful completion of internship. El was assessed with self-administered Genos Emotional Intelligence Full Version (70 questions equally weighted: total score 350). Demographic and internship-related data were obtained using a self-administered questionnaire.

Results: Of 130 eligible post-interns, 88 responded (response rate-67.7\%). 67\% were women, mean age was $28.3 \pm 0.9$ years. Post-intern mean El score was significantly lower than the pre-intern score $(232.7 \pm 14.9$ vs $241.7 \pm 23.3 ; p=0.004)$. Compared to pre-intern El, post-intern El has improved in men but has deteriorated in women (change in El score: $2.1 \pm 37.2$ in men; $-14.5 \pm 22$ in women; $p=0.01$ ). There was no statistically significant difference in the change in El based on final MBBS result, marital status, specialties chosen for internship, type of hospital (teaching vs non-teaching) or unit (professorial vs non-professorial) where internship was done, number of co-house-officers or presence of post-graduate trainees in the unit.
Conclusions: In the study population, EI has significantly deteriorated during internship training. Overall deterioration was mainly due to the reduction of El in women. Introducing programmes to improve El of junior doctors is as important as improving clinical knowledge and skills.

Key words: emotional intelligence, internship training, medical graduates, Sri Lanka

\section{Introduction}

Emotional intelligence (EI) is defined as "the ability to monitor one's own and other people's emotions, to discriminate between different emotions and label them appropriately, and to use emotional information to guide thinking and behaviour and to manage and/or adjust emotions to adapt environments or achieve one's goals". ${ }^{1}$ The two aspects of emotional intelligence are interpersonal and intrapersonal intelligence. Interpersonal intelligence is useful to understand and manage relationships with the other people which in turn helps to develop qualities like empathy and to build up positive relationships. Intrapersonal intelligence is used to become aware and to understand oneself. This kind of self-awareness is important for self-regulation and self-motivation. A higher El is likely to be associated with a greater ability to understand, regulate, and manage emotions related to oneself and the others.

Evidence from different populations indicate that El has a positive impact on academic and professional success in the field of medicine and others. ${ }^{2-12}$ Previous

${ }^{1}$ Department of Pharmacology, Faculty of Medical Sciences, University of Sri Jayewardenepura, Gangodawila, Nugegoda, Sri Lanka, ${ }^{2}$ Colombo South Teaching Hospital, Kalubowila, Sri Lanka.

Correspondence: CNW, e-mail: nirmalawijekoon@sjp.ac.lk

https://orcid.org/0000-0003-1315-2460

Received 20 August 2021, accepted 18 October 2021

This is an open-access article distributed under the terms of the Creative Commons Attribution License, which permits unrestricted use, distribution, and reproduction in any medium, provided the original author and source are credited. 
studies have shown that El is associated with improved empathy during medical consultation, ${ }^{13}$ better doctorpatient relationships, ${ }^{13}$ better clinical performance, ${ }^{14,15}$ and higher patient satisfaction. ${ }^{16}$ These findings highlight the importance of El in making a competent and well-balanced doctor who looks after the overall well-being of the patients. Furthermore, El is important for better self-care of doctors who constantly face emotionally demanding situations.

Even though El has gained a lot of attention with regard to academic and work performance globally, there is scarcity of such data from Sri Lanka. We planned a study to evaluate the effect of internship training on $\mathrm{El}$ in a group of Sri Lankan doctors. Determining the effect of internship training on El and identifying the factors associated with changes in EI are important for developing strategies to improve El in doctors in Sri Lanka.

\section{Methods}

This was a descriptive follow up study with pre and post exposure data collection. The participants were post-intern medical officers graduated from a medical faculty in Sri Lanka who had already participated in the baseline study during their pre-intern period. All those who were registered at the selected medical faculty and sat for the final MBBS examination in their first attempt in January 2016 were eligible for the baseline study. Detailed methodology of the baseline study is already published. ${ }^{9}$ The inclusion criteria for the follow up study were being a participant of the baseline study conducted in 2016, successful completion of internship within 3 months and availability of meaningful consent. Exclusion criterion was the inability to complete the internship successfully.

Written informed consent was obtained from all participants prior to recruitment. The ethical approval for the study was obtained from Ethics Review Committee of the Faculty of Medical Sciences, University of Sri Jayewardenepura, Sri Lanka (Ref. No. 79/17).

\section{Sampling}

Consecutive sampling was done. All participants of the pre-intern baseline study were invited to join the post-intern follow up study. The number of participants of the baseline study was 130 .

\section{Study instruments}

El was assessed with self-administered Genos Emotional Intelligence Full Version (Genos El inventory). ${ }^{17}$ Prior permission was obtained to use this tool for research purposes. It was administered in the original language which was English. This tool has seventy items in seven different domains of El. It quantifies how frequently a person behaves in an emotionally intelligent manner. The seven domains include: emotional self-awareness, emotional expression, emotional awareness of others, emotional reasoning, emotional self-management, emotional management of others and emotional self-control. The items are scored on a five-point Likert scale, consisting of 'Almost Never', 'Seldom', 'Sometimes', 'Usually' and 'Almost Always'. The maximum score for each item in this 70 -item tool is 5 . The maximum total score is 350 and maximum score for each domain is $50 .{ }^{17} \mathrm{~A}$ selfadministered questionnaire was used to collect the sociodemographic details and the details related to the internship appointments. The data related to EI scores of the same cohort collected in the pre-intern period by the investigators were used for the comparison between pre-intern and post-intern El. ${ }^{9}$

\section{Data collection procedure}

The potential participants were contacted via email and telephone and invited to participate in the study. The electronic versions of the study instruments (as google forms) were sent to the potential participants via email. The participants were assigned the same study number they had for the baseline study. The participant information sheet and the consent form were also incorporated into the electronic form along with the study instruments. In the electronic form the participant information sheet and the consent form appeared before the study instruments and those who were consenting were able to proceed to complete the study instruments. The facility to clarify queries related to the study was made available to all participants.

\section{Statistical analysis}

Data collected via the electronic forms were transported to SPSS for analysis. Data analysis was done with SPSS version 21. Percentages and means were used to describe sociodemographic characteristics and El scores. The paired sample t-test was used to compare the means of the pre-internship and post-internship EI scores. The independent sample t-test was used to compare the change in the mean El scores based on the internship related factors, final MBBS result and the marital status when there were only two groups and ANOVA was used when there were more than two groups. $P$ value less than 0.05 was considered statistically significant. 


\section{Results}

Out of 130 eligible individuals, 88 participated in the follow-up study (response rate $67.7 \%$ ). $67 \%$ were women and the mean age was $28.3 \pm 0.9$ years. Overall, the post-intern total El score was significantly lower than the pre-intern total EI Score. (post-intern:
232.7 \pm 14.9 ; pre-intern: 241.7 $\pm 23.3 ; p=0.004)$. Gender wise analysis showed that compared to pre-intern mean El score, post-intern mean El score has improved non significantly by 2.1 marks in men but has deteriorated significantly by 14.5 marks in women (Table 1).

Table 1. Pre and post-intern total El score in men and women

\begin{tabular}{lcccc}
\hline & $\begin{array}{c}\text { Pre-intern El } \\
\text { score }\end{array}$ & $\begin{array}{c}\text { Post-intern El } \\
\text { score }\end{array}$ & $\begin{array}{c}\text { Change in El } \\
(95 \% \mathrm{Cl})\end{array}$ & $P$ value \\
\hline Men $(\mathrm{n}=29)$ & 235.6 & 237.7 & $2.1(-12.0$ to 16.3$)$ & 0.759 \\
Women $(\mathrm{n}=59)$ & 244.7 & 230.2 & $-14.5(-20.2$ to -8.7$)$ & $<0.001$ \\
Overall $(\mathrm{n}=88)$ & 241.7 & 232.7 & $-8.9(-15.1$ to -2.9$)$ & 0.004 \\
\hline
\end{tabular}

El $=$ Emotional intelligence

The domains which had a significant deterioration between pre- and post-intern scores were emotional selfawareness, emotional awareness of others, emotional management of others and emotional self-control. It was most prominent with regard to emotional awareness of others (Table 2).

Table 2. Pre and post-intern El score in the seven domains

\begin{tabular}{lcccc}
\hline El Domain & $\begin{array}{c}\text { Pre-intern El } \\
\text { score }\end{array}$ & $\begin{array}{c}\text { Post-intern El } \\
\text { score }\end{array}$ & $\begin{array}{c}\text { Change in El } \\
\text { (95\% Cl) }\end{array}$ & $P$ value \\
\hline Emotional Self-Awareness (ESA) & 36.8 & 35.8 & $-1.0(-1.6$ to -0.5$)$ & $<0.001$ \\
Emotional Expression (EE) & 32.6 & 33.0 & $0.4(-0.3$ to 1.1) & 0.217 \\
Emotional Awareness of Others (EAO) & 35.4 & 29.9 & $-5.5(-6.0$ to -5.0$)$ & $<0.001$ \\
Emotional Reasoning (ER) & 34.6 & 35.0 & $0.4(-0.3$ to 1.2) & 0.229 \\
Emotional Self-Management (ESM) & 33.3 & 33.9 & $0.6(-0.1$ to 1.2) & 0.079 \\
Emotional Management of Others (EMO) & 35.5 & 34.0 & $-1.5(-2.0$ to -0.9$)$ & $<0.001$ \\
Emotional Self-Control (ESC) & 33.4 & 31.2 & $-2.2(-2.9$ to -1.5$)$ & $<0.001$ \\
\hline
\end{tabular}

$\mathrm{EI}=$ Emotional intelligence

There was no statistically significant difference in the change in mean El score between pre-intern assessment and post-intern assessment based on internship related factors, final MBBS result or marital status (Table 3). 
Table 3. Change in total El score based on internship related factors, final MBBS result and social status

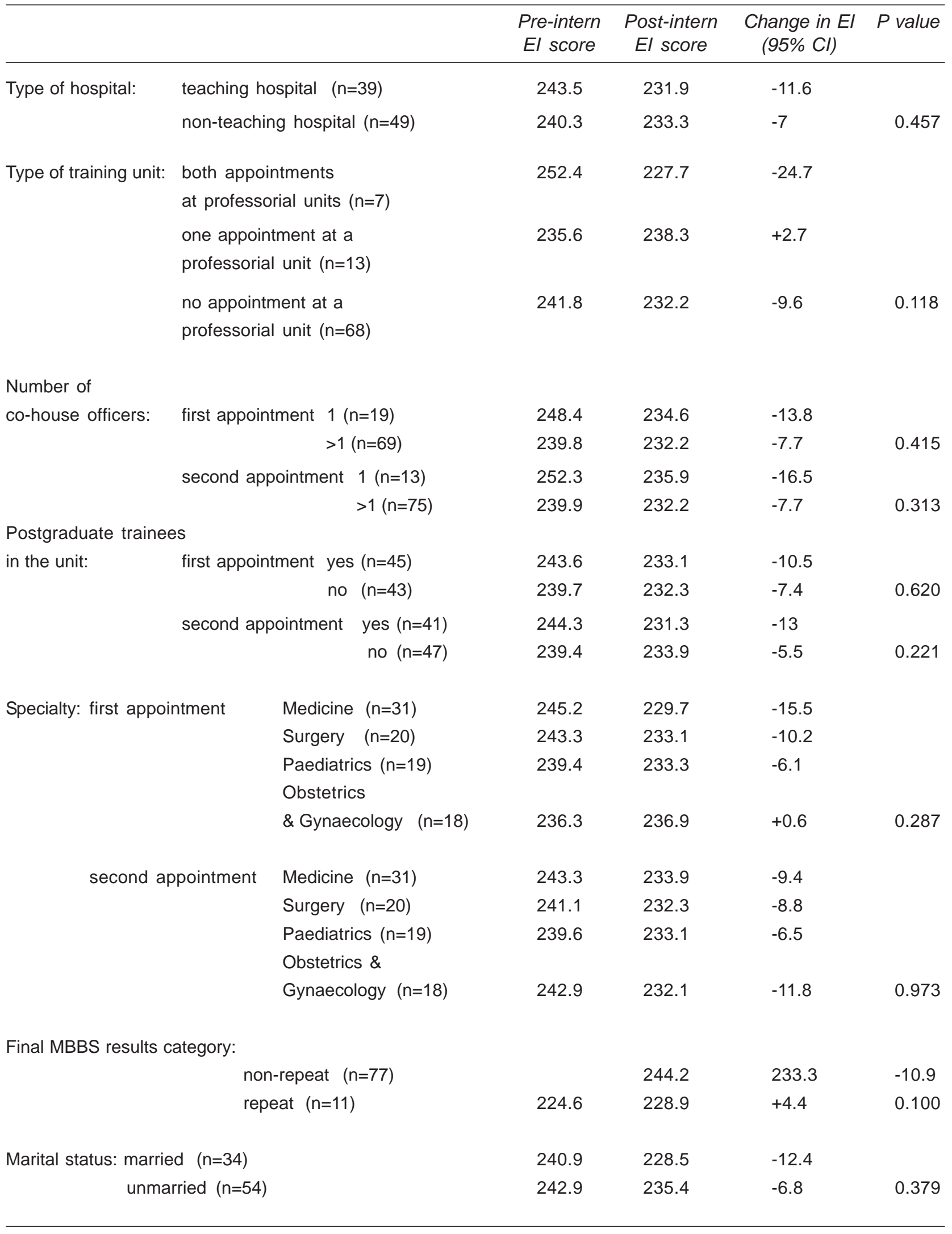

EI = Emotional intelligence; MBBS = Bachelor of Medicine Bachelor of Surgery 


\section{Discussion}

We found that in the study population, El has significantly deteriorated during the internship training. When we looked at the gender-based changes in El score it was apparent that the overall deterioration was mainly due to the significant reduction of El in women. In men there was a non-significant improvement in the El.

One might expect the El to improve with experience gained during internship training as there is ample opportunity to be exposed to emotionally demanding situations in the interactions with the patients, care givers and members of the healthcare team. It was expected that the training and guidance provided by the senior members of the health care team would contribute to improved El. What we actually observed in the majority of the study participants was the opposite. The El deteriorated during the internship.

Literature provides evidence to indicate that there is a negative correlation between stress and El. ${ }^{10,18-26}$ Some studies have interpreted this as El being protective against stress. ${ }^{19,21,25}$ However, it is difficult to interpret the cause and effect with cross-sectional studies. Theoretically an individual with a higher level of $\mathrm{El}$ is more likely to show an adaptive response to a stressful situation. On the other hand, there is a possibility of El deteriorating with high level of stress. A systematic review by Lea et al. has reported that EI was adaptive in certain circumstances only, and that findings varied based on the type of stress. ${ }^{27}$

High level of stress is a likely cause for the deterioration in El we observed in this study. The internship is a stressful period for the new medical graduates as a result of multiple reasons including limited experience, high workload, long working hours and sleep deprivation. It is possible that the El of the participants deteriorated due to the work-related stress experienced during the internship. A previous study including postgraduate medical students in India has shown that El decreases with high workload, having night duty hours and having emergency duty. ${ }^{28}$ Another study done in medical postgraduates in India has reported that those who had less work load, had higher El scores. ${ }^{29}$

We observed a gender-based difference in changes of El between pre and post intern periods. It is possible that men and women respond to stress differently, and the different responses could be the reason for the deterioration of $\mathrm{El}$ in women compared to men. In literature, gender has been described as an important determinant of vulnerability to psychosocial stress. ${ }^{30,31}$ Men and women tend to have psychological and biological differences with regard to stress reactivity. ${ }^{32,33}$ Prior studies have shown various genderbased differences that increase endocrine, emotional, and arousal responses to stress in women making them more vulnerable to emotional distress. ${ }^{34}$ Cyranowski et al has proposed that women are more likely to be negatively affected by interpersonal events. ${ }^{35}$ During the pre-intern period women had a significantly higher El score than men. ${ }^{9}$ However, in the post-intern follow up study, deterioration of El was observed in women but not in men. This finding raises the question whether those with higher El are more vulnerable to deterioration of $\mathrm{El}$ as a response to stressful situations.

Contrary to what we believed, the nature of the training unit, number of co-house officers or presence of post-graduate trainees in the unit did not have a significant impact on the change in El. There was no difference in the change in El based on the specialty of the unit where internship was done, the performance of the participant at the final MBBS examination and the marital status.

It has been previously reported that EI has a positive impact on empathy, doctor-patient relationship, and clinical performance. ${ }^{13-15}$ Previous studies have also shown that higher level of El is associated with better physical and mental health, ${ }^{36,37}$ lower anxiety and depression in adolescents ${ }^{38}$ and adult students. ${ }^{39}$ Thus, it is likely that the deterioration in El during internship has negative implications such as poor work performance, lack of empathy, poor interpersonal relationships with patients as well as with other members of the healthcare team and being victimized to burnout, anxiety and depression. The most prominent deterioration in the study population was in the domain "emotional awareness of the others". This is likely to affect empathy which is an essential quality for a doctor.

Attention needs to be paid to seek methods to prevent deterioration and to further improve $\mathrm{El}$ of these young doctors who are just beginning their career. EI can be improved through training. A few studies from developed countries have shown that various training strategies have enhanced El and positively influenced health care outcomes. ${ }^{40-44}$

Introducing programmes to improve $\mathrm{El}$ is as equally important as improving the clinical knowledge and skills in order to produce well-balanced doctors who are competent at practicing the science as well as the art of medicine. Identifying the reasons for the deterioration in El during internship is another important aspect which is essential for planning remedial measures. A qualitative study might be useful to explore and understand these reasons better. 
Our study had a few limitations. One major limitation was that we did not objectively assess the stress level of the participants in the pre- and postintern periods. It limits our ability to correlate the level of El with the level of stress. If we had a qualitative component to the study, we could have had a better understanding of the reasons for deterioration in El. This was another limitation. Furthermore, our study participants were medical graduates of a single university. Thus, the generalizability of the study findings is limited.

\section{Conclusions}

In the study population, El deteriorated significantly during the internship training. The observed overall deterioration was mainly due to the significant reduction of $\mathrm{El}$ in women. Final MBBS results, marital status, and the internship related factors such as the training unit, specialty, number of co-house officers or presence of postgraduate trainees did not have a significant impact on the change in El. Introducing programs to improve El of junior doctors is as equally important as improving the clinical knowledge and skills.

\section{Source(s) of support}

This is a self-funded study.

\section{Conflicts of Interest}

There are no conflicts of interest.

\section{References}

1. Coleman AM. A Dictionary of Psychology. $3^{\text {rd }}$ Ed. Oxford University Press. 2008.

2. Romanelli F, Cain J, Smith KM. Emotional intelligence as a predictor of academic and/or professional success. Am J Pharm Educ. 2006; 70(3): 69.

3. Chew BH, Zain AM, Hassan F. Emotional intelligence and academic performance in first and final year medical students: a cross-sectional study. BMC Med Educ 2013; 13: 44 .

4. Victoroff, KZ, Boyatzis RE. What is the relationship between emotional intelligence and dental student clinical performance? J Dent Educ 2012; 77: 416-26.

5. Kumar A, Puranik MP, Sowmya KR. Association between dental students' emotional intelligence and academic performance: a study at six dental colleges in India. J Dent Educ 2016; 80: 526-32.

6. Beauvais AM, Brady N, O'Shea ER, Griffin MT. Emotional intelligence and nursing performance among nursing students. Nurse Educ Today 2011; 31: 396-401.
7. Fernandez R, Salamonson Y, Griffiths R. Emotional intelligence as a predictor of academic performance in first year accelerated graduate entry nursing students. J Clin Nurs 2012; 21: 3485-92.

8. Austin EJ, Evans P, Magnus B, O'Hanlon K. A preliminary study of empathy, emotional intelligence, and examination performance in MBChB students. Med Educ 2007; 41: 684-89.

9. Wijekoon CN, Amaratunge $\mathrm{H}$, de Silva $\mathrm{Y}$, Senanayake $\mathrm{S}$, Jayawardane P, Senarath U. Emotional intelligence and academic performance of medical undergraduates: a crosssectional study in a selected university in Sri Lanka. BMC Med Educ 2017; 17: 176.

10. Ranasinghe $P$, Wathurapatha WS, Mathangasinghe $Y$, Ponnamperuma G. Emotional intelligence, perceived stress, and academic performance of Sri Lankan medical undergraduates. BMC Med Educ 2017; 17: 41.

11. Sánchez-Álvarez N, Berrios Martos MP, Extremera N. AMetaAnalysis of the Relationship Between Emotional Intelligence and Academic Performance in Secondary Education: A Multi-Stream Comparison. Front Psychol. 2020; 11: 1517.

12. Thacoor A, Smith O, Nikkhah D. The Role of Emotional Intelligence in Predicting a Successful Career for Plastic Surgeons: A Systematic Review. Plast Reconstr Surg Glob Open 2020; 8: e2699.

13. Arora S, Ashrafian H, Davis R, Athanasiou T, Darzi A, Sevdalis $\mathrm{N}$. Emotional intelligence in medicine: a systematic review through the context of the ACGME competencies. Med Educ. 2010; 44: 749-64.

14. Satterfield J, Swenson S, Rabow M. Emotional intelligence in internal medicine residents: Educational implications for clinical performance and burnout. Ann Behav Sci Med Educ 2009; 14: 65-8.

15. Stratton TD, Elam CL, Murphy-Spencer AE, Quinlivan SL. Emotional intelligence and clinical skills: preliminary results from a comprehensive clinical performance examination. Acad Med 2005; 80: S. 34-7.

16. Blue AV, Chessman AW, Gilbert GE, Mainous AG 3rd. Responding to patients' emotions: important for standardized patient satisfaction. Fam Med 2000; 32: 326-30.

17. Gignac GE. Genos Emotional Intelligence Inventory: Technical Manual. 2nd Ed. Genos Pty Ltd. 2010. https://www. genosnorthamerica.com/wp-content/uploads/2019/11/ Genos-Emotional-Intelligence-Inventory-Technical-Manual2nd-Edition1.pdf

18. Doyle NA, Davis RE, Quadri SSA,et al. Associations between stress, anxiety, depression, and emotional intelligence among osteopathic medical students. J Osteopath Med 2021; 121: 125-13.

19. Foster K, Fethney J, Kozlowski D, Fois R, Reza F, McCloughen A. Emotional intelligence and perceived stress of Australian pre-registration healthcare students: A multi- 
disciplinary cross-sectional study. Nurse Educ Today 2018; 66: 51-6.

20. Jung Y, Shin NY, Jang JH, Lee WJ, Lee D, Choi Y, Choi S, Kang D. Relationships among stress, emotional intelligence, cognitive intelligence, and cytokines. Medicine 2019; 98 : 18.

21. Molero Jurado MDM, Pérez-Fuentes MDC, Oropesa Ruiz NF, Simón Márquez MDM, Gázquez Linares JJ. Self-Efficacy and Emotional Intelligence as Predictors of Perceived Stress in Nursing Professionals. Medicina 2019; 55: 237.

22. Cejudo J, Rodrigo-Ruiz D, López-Delgado ML, Losada L. Emotional Intelligence and Its Relationship with Levels of Social Anxiety and Stress in Adolescents. Int. J. Environ. Res. Public Health 2018; 15: 1073.

23. Yadav V, Mohanty V, Balappanavar AY, Verma A, Chahar P, Yadav G. Emotional Intelligence and Perceived Stress among Dental Undergraduates in Delhi. Int J Clin Pediatr Dent 2020; 13: $344-7$

24. Yaseen YA, Abdulah DM, Piro RS. Emotional intelligence dimensions as predictors of coping reactions to stress in nursing practitioners. Fukushima J. Med. Sci 2019; 65: 99-108.

25. Mikolajczak M, Petrides KV, Coumans N, Luminet O. The moderating effect of trait emotional intelligence on mood deterioration following laboratory-induced stress. Int. J. Clin. Health Psychol. 2009; 9: 455-77.

26. Extremera N, DuránA, Rey L. Perceived emotional intelligence and dispositional optimism-pessimism: analyzing their role in predicting psychological adjustment among adolescents. Pers. Individ. Dif. 2007; 42: 1069-79.

27. Lea RG, Davis SK, Mahoney B, Qualter P. Does Emotional Intelligence Buffer the Effects of Acute Stress? A Systematic Review. Front. Psychol. 2019; 10: 810.

28. Ravikumar R, Rajoura OP, Sharma R, Bhatia MS. A Study of Emotional Intelligence Among Postgraduate Medical Students in Delhi. Cureus 2017; 9: e989.

29. Faye A, Kalra G, Swamy R, Shukla A, Subramanyam A, Kamath R. Study of emotional intelligence and empathy in medical postgraduates. Indian J Psychiatry 2011; 53: 140-44.

30. Wang J, Korczykowski M, Rao H, et al. Gender difference in neural response to psychological stress. Soc Cogn Affect Neurosci 2007; 2: 227-39.

31. Stroud LR, Salovey P, Epel ES. Sex differences in stress responses: social rejection versus achievement stress. Biol Psychiatry 2002; 52: 318-27.
32. Gender differences in stress response: Role of developmental and biological determinants. Verma R, Balhara YPS, Gupta CS. Ind Psychiatry J. 2011; 20(1): 4-10.

33. Gender Differences in Neural Correlates of Stress-Induced Anxiety Seo D, AhluwaliaA, Potenza MN, Sinha R. J Neurosci Res. 2017; 95(1-2): 115-25.

34. Sex Differences in Stress-Related Psychiatric Disorders: Neurobiological Perspectives. Bangasser DA, Valentino RJ. Front Neuroendocrinol. 2014; 35(3): 303-19.

35. Cyranowski JM, Frank E, Young E, Shear MK. Adolescent onset of the gender difference in lifetime rates of major depression: a theoretical model. Arch Gen Psychiatry 2000; 57: 21-7.

36. Martins A, Ramalho N, and Morin EA. comprehensive metaanalysis of the relationship between emotional intelligence and health. Pers. Individ. Dif. 2010; 49: 554-64.

37. Sánchez-Álvarez N, Extremera N, Fernández-Berrocal P. The relation between emotional intelligence and subjective well-being: a metanalytic investigation. J. Posit. Psychol. 2015; 11: 276-85.

38. Resurrección DM, Salguero JM, Ruiz-Aranda D. Emotional intelligence and psychological maladjustment in adolescence: a systematic review. J. Adolesc. 2014; 37: 461-72.

39. Ahmadpanah M, Keshavarz M, Haghighi M, Jahangard L, Bajoghli $H$, Sadeghi Bahmani D, et al. Higher emotional intelligence is related to lower test anxiety among students. J. Neuropsychiatr. Dis. Treat. 2016; 12: 133-6.

40. Nelis D, Quoidbach J, Mikolajczak M, Hansenne M. Increasing emotional intelligence: (How) is it possible? Pers Individ Differ 2009; 47: 36-41.

41. Grant AM. Enhancing coaching skills and emotional intelligence through training. Ind Commer Train 2007; 39: 257-66.

42. Cerrone SA, Adelman P, Akbar S, Yacht AC, Fornari A. Using Objective Structured Teaching Encounters (OSTEs) to prepare chief residents to be emotionally intelligent leaders. Med Educ Online 2017; 22: 1320186.

43. Dugan JW, Weatherly RA, Girod DA, Barber CE, Tsue TT.A longitudinal study of emotional intelligence training for otolaryngology residents and faculty. JAMA Otolaryngol Head Neck Surg. 2014; 140: 720-6.

44. Gorgas DL, Greenberger S, Bahner DP, Way DP, Teaching Emotional Intelligence: A Control Group Study of a Brief Educational Intervention for Emergency Medicine Residents. West J Emerg Med 2015; 16: 899-906. 